\title{
Estrategias de rastreo de cáncer cervicouterino con citología y prueba del virus del papiloma humano
}

\author{
Strategies for cervical cancer screening with cytology and human papillomavirus testing
}

\section{Objetivos}

Comparar la eficacia de diez estrategias de rastreo de cáncer cenvicouterino (CCU) que combinan la prueba de detección del virus del papiloma humano (VPH) y la citología con técnica de Papanicolaou (PAP).

\section{Diseño}

Estudio secundario realizado a partir del ensayo clínico ATHENA (Addressing The Need for Advanced HPV Diagnostics) ${ }^{1}$ diseñado para comparar el rédito diagnóstico de la prueba Cobas HPV-test (Roche) combinada con la citología cervical.

\section{Lugar}

El análisis comparativo de la sensibilidad, la especificidad y el número necesario de colposcopias para la detección de una lesión adicional de alto grado con las diferentes estrategias (aquí resumido y comentado) fue realizado en Londres, Gran Bretaña, pero a partir de datos obtenidos del ensayo aleatorizado ATHENA, que se desarrolló en EE.UU.

\section{Pacientes}

El ensayo ATHENA había enrolado 47.000 mujeres mayores de 21 años que habían realizado citología cervical líquida y prueba de VPH. El trabajo aquí comentado, que se desprende del mencionado, incluyó y analizó la información de aquellas mujeres mayores de 30 años de edad con prueba VPH positiva y/o citología con células atípicas escamosas de significancia indeterminada (en inglés Atypical Squamous Cells of Undetermined Significance: ASCUS) o mayor grado de displasia $\left(\mathrm{ASCUS}+{ }^{\S}\right)$ que hubieran tenido seguimiento colposcópico. Resultaron elegibles 34.254 mujeres con una edad promedio de 44,7 (37,2\% estaba cursando el climaterio). El 91\% había realizado citología de PAP durante los cinco años previos y sólo el 0,1\% había recibido vacunación anti VPH.

\section{Intervención}

Fueron comparadas diez estrategias de rastreo (ver cuadro 1) respecto de su rédito diagnóstico y del número de colposcopias necesarias para detectar una lesión intraepitelial por anatomía patológica.

Cuadro 1: estrategias diagnósticas comparadas.

1. Citología y test VPH en pacientes con ASCUS: seguimiento citológico habitual para frotis normal / colposcopía si la citología es ASCUS / citología y colposcopia si es ASCUS+.

2. Citología sola: seguimiento citológico habitual para frotis nor$\mathrm{mal} /$ colposcopia si ASCUS+.

3. Cotesting o doble prueba con test VPH y citología: Seguimiento habitual si ambos son negativas / Colposcopía si test VPH+ y/o ASCUS / Cotest al año si no hay lesión epitelial y VPH+.

4. Test VPH con búsqueda genotipo VPH16/18 y citología (Cotest o doble prueba): Colposcopía si ASCUS+ o VPH 16/18 positiva.
Cox J y col. Am J Obstet Gynecol 2013;208:184.e1-11.

5. Test VPH con búsqueda genotipo VPH16 /18 y citología (Cotest o doble prueba): Colposcopía ante SIL+ o ASCUS o prueba de VPH 16/18 positiva.

6 . Test VPH solo: rastreo habitual si el resultado es negativo y colposcopia si es positivo.

7. Test VPH y citología: citología si VPH positivo. Si la citología es normal, rastreo habitual. Si la citología es ASCUS+, colposcopia. 8. Test VPH con búsqueda de genotipo VPH 16/18: Si es VPH y búsqueda de genotipo 16/18 son negativo se indica citología. Colposcopia si la prueba de VPH $16 / 18$ es positiva. Seguimiento al año para otros genotipos VPH positivos.

9. Test VPH con búsqueda VPH 16/18, colposcopia ante VPH 16/18 positiva. Citología para otros genotipos VPH positivos y colposcopia si la citología es ASCUS+.

10. Test VPH con búsqueda VPH 16/18, colposcopia para VPH 16/18 positiva. Citología para otros genotipos VPH positivos. Seguimiento al año si la citología es normal o ASCUS. Colposcopia para LSIL+.

\section{Medición de resultados principales}

Como puntos finales fueron consideradas las lesiones colposcópicas con una displasia igual o superior a CIN2 (CIN2+) y a CIN3 (CIN3+). Para cada una de las estrategias de rastreo se evaluó la sensibilidad, la especificidad, la tasa de falsos positivos (TFP) y negativos (TFN), y el número de colposcopías necesarias para el diagnóstico de una lesión adicional de alto grado (CIN2+ y CIN3+), en comparación con las que habrían sido detectadas con la estrategia Nro 1 (estrategia de referencia). Tanto las participantes como los colposcopistas estuvieron ciegos a los resultados obtenidos en la estrategia de cribado, y los resultados de las biopsias fueron revisados por un panel de tres patólogos expertos.

\section{Resultados Principales}

Como era esperable, la implementación de estrategias más sensibles resultó en mayores requerimientos de colposcopía. La estrategia "Sólo prueba de VPH" fue la de mayor sensibilidad para detección de CIN2+. Cuando a un resultado positivo de la prueba de VPH se lo combina con la exigencia de alteraciones en el extendido citológico, la sensibilidad se ve reducida, aumentando la especificidad; mientras que las estrategias de doble prueba o "cotesting", al discriminar por tipo VPH 16 o 18 reducen aún más la necesidad de evaluación colposcópica. La estrategia 6 , de test VPH es la más sensible $(89,9 \%)$ pero con una tasa de $38 \%$ de falsos positivos, mientras la 9 y la 10 (de pruebas combinadas) balancean aceptablemente la sensibilidad y la tasa de falsos positivos. Los autores concluyen que con la estrategia 4 (cotesting y tipificación de virus 16 y 18) se agrega una medida intermedia. La tabla 1 resume los resultados para cada estrategia en relación a su tasa de detección de lesiones CIN2+/3+.

Tabla 1: resultados para cada estrategia en relación a la detección de CIN2+/CIN3+

\begin{tabular}{c|c|c|c|c|c|c|c|c}
\multirow{2}{*}{ Estrategia } & \multicolumn{2}{|c|}{$\begin{array}{c}\text { Número absoluto de pruebas } \\
\text { realizadas }\end{array}$} & \multicolumn{3}{c|}{ Detección de lesiones CIN2 o de mayor grado de } & \multicolumn{3}{c}{$\begin{array}{c}\text { Detección de lesiones CIN3 o de mayor grado de } \\
\text { displasia }\end{array}$} \\
\cline { 2 - 10 } & HPV o citología & Colposcopias & NNC & Sensibilidad (\%) & TFP (\%) & NNC & Sensibilidad (\%) & TFP (\%) \\
\hline 1 & 35.546 & 816 & 5,7 & 51,4 & 12,0 & 7,7 & 56,1 & 12,4 \\
\hline 2 & 34.254 & 1644 & 11,0 & 53,2 & 26,6 & 15,1 & 57,7 & 26,8 \\
\hline 3 & 68.508 & 816 & 5,7 & 51,4 & 12,0 & 7,7 & 56,1 & 12,4 \\
\hline 4 & 68.508 & 1202 & 6,4 & 67,5 & 18,0 & 8,3 & 76,2 & 18,5 \\
\hline 5 & 68.508 & 1030 & 6,0 & 61,8 & 15,2 & 7,7 & 70,9 & 15,7 \\
\hline 6 & 34.254 & 2341 & 9,7 & 86,4 & 37,3 & 13,8 & 89,9 & 38,0 \\
\hline 7 & 37.126 & 596 & 4,5 & 47,5 & 8,2 & 6,1 & 51,9 & 8,7 \\
\hline 8 & 34.254 & 580 & 4,8 & 43,6 & 8,1 & 5,7 & 53,4 & 8,4 \\
\hline 9 & 36.423 & 982 & 5,5 & 63,6 & 14,3 & 7,2 & 72,0 & 14,8 \\
\hline 10 & 36.423 & 810 & 5 & 57,9 & 11,5 & 6,4 & 66,7 & 12,0 \\
\hline
\end{tabular}

TFP: tasa de falsos positivos. NNC: número de colposcopías necesarias para detectar una lesión adicional a las que habrían sido detectadas con la estrategia que se usó como referencia (estrategia Nro 1). 


\section{Conclusiones}

Las estrategias que maximizan la detección de mujeres con mayor riesgo de neoplasia cervical implican una mayor probabilidad de que requiera ser derivada para ser evaluada a través de una colposcopía; mientras que las que incorporan una segunda prueba maximizan el beneficio y reducen los potenciales daños. Por ejemplo, la pesquisa conjunta de los tipos virales 16 y 18 del VPH con la citología provee un balance ade- cuado entre sensibilidad y especificidad, limitando el número de colposcopias.

Fuente de financiamiento: Roche Molecular Systems. Conflicto de interés de los autores: los dos primeros autores recibieron beneficios económicos de Merk en relación a la vacuna VPH y de Roche y Qiagen por presentaciones y educación médica sobre pruebas de captura hibrida y tipificación para VPH (tecnologías desarrolladas por estas empresas).

\section{Comentario}

Desde la introducción de la citología de cérvix uterino como método de rastreo se ha documentado una reducción significativa de la mortalidad por CCU en los países desarrollados, lo que no ha ocurrido en América Latina ${ }^{2: 3}$ (a pesar de que en esta región existen programas nacionales vigentes para la prevención y el control del CCU).

En Argentina mueren 2800 mujeres por año por CCU, representando la segunda causa de muerte por cáncer en mujeres ${ }^{4}$. La Encuesta Nacional de Factores de Riesgo informa que la cobertura en Argentina del rastreo es en promedio de $60 \%$ para todo el territorio, pero menos del $47 \%$ en el Noroeste y el Noreste Argentino (NOA y NEA). La variabilidad entre las regiones se ve reflejada en la tasa de mortalidad, más elevada en dichas regiones ${ }^{5}$.

Dado que la técnica de PAP tiene una sensibilidad de 60 a $70 \%$ es necesaria su repetición a intervalo recomendados (anualmente durante dos oportunidades y luego cada tres años, ante resultados negativos). Es por eso que si uno deja de lado las barreras subjetivas y culturales, la mortalidad por CCU expresa básicamente desigualdad en el acceso a los Servicios de Salud, fundamentalmente para los segmentos más pobres de la población.

Dada las barreras al acceso, al momento de diseñar una estrategia de cribado, cobra importancia el análisis del rédito diagnóstico de las nuevas tecnología con mayor sensibilidad y alto valor predictivo negativo, lo que puede redundar en que puedan ser aplicadas a intervalos más prolongados.
Durante la última década se avanzó en el conocimiento sobre el papel del VPH en la fisiopatogenia de la displasia de alto grado y del $\mathrm{CCU}^{6-7}$. Estos avances han favorecido el desarrollo de nuevas tecnologías para su control, entre ellas la detección del virus por captura hibrida.

En la actualidad, la estrategia de prevención del CCU en Argentina es integrada e incluye la vacunación de niñas de 11 años y la pesquisa de lesiones por citología o captura hibrida de VPH junto a la citología cervical. Esta estrategia de rastreo combinada ("cotesting") ${ }^{8}$ cuenta con respaldo bibliográfico.

\section{Conclusiones de la comentadora}

El trabajo que hemos resumido comparó diferentes estrategias de rastreo aplicadas en serie o en paralelo e incluyó también una modalidad de reciente disponibilidad que es la identificación de los tipos 16 y 18 de VPH. Si bien su diseño y su reporte son claros y prolijos, podrían cuestionarse los vínculos de sus autores con la industria y sus conflictos de intereses. Consideramos que la principal fortaleza de esta investigación es que ofrece una estimación de los requerimientos de recursos técnicos y humanos de cada una de las estrategias analizadas, lo que puede ayudar a definir la más conveniente para cada región de acuerdo a los recursos disponibles (colposcopios y colposcopistas, laboratorios, técnicos, etc.).

Vilda Discacciati [ Servicio de Medicina Familiar y Comunitaria del Hospital Italiano de Buenos Aires y Departamento de Salud Pública del Instituto Universitario Hospital Italiano de Buenos Aires. vilda.discacciati@ hiba.org.ar]

Discacciati V. Estrategias de rastreo de cáncer cervicouterino con citología y prueba del virus del papiloma humano. Evid Act Pract Ambul.2014 17(4). Oct-Dic 131-132. Comentado de : Cox J y col. Comparison of cervical cancer screening strategies incorporating different combinations of cytology, HPV testing, and genotyping for HPV 16/18: results from the ATHENA HPV study. Am J Obstet Gynecol 2013; 208:184.e1-11. PMID: 23174289.

\section{Referencias}

1. Wright T y col. The ATHENA human papillomavirus study: design, methods, and baseline results. Am J Obstet Gynecol 2012; $206: 46 . e 1-11$.

2. Sasieni P y col. Effect of screening on cervical cáncer mortality in England and Wales: analysis of trends with an age period cohort model. BMJ 1999,318 (7193):1244-5. Hakama M et al. A screening programme for cervical cáncer that worked. Cáncer Surv 1988; 7(3): 403-16.

3. Almonte y col. Nuevos paradigmas y desafíos en la prevención y control del cáncer de cuello uterino en América Latina. Salud Pública Méx 2010; Vol. 52(6):544-559

4. Proyecto para el mejoramiento del Programa Nacional de Prevención de Cáncer de Cuello Uterino en Argentina. Ministerio de Salud de la Nación 2007. (http://www.msal.gov.ar/inc/images/stories/downloads/publicaciones/equipo_medico/Diagnostico_Pub64_OPS.pdf).

5. Ferrante D y col. Encuesta Nacional de Factores de Riesgo 2009: evolución de la epidemia de enfermedades crónicas no transmisibles en Argentina. Rev Argent salud Pública, 2011; 2(6):34-41.

6. Insinga y col. Epidemiologic natural history and clinical management of Human Papillomavirus (HPV) Disease: a critical and systematic review of the literature in the development of an HPV dynamic transmission model. BMC Infectious Diseases 2009, 9:119.

7. Rodríguez y col. Longitudinal Study of Human Papillomavirus Persistence and Cervical Intraepithelial Neoplasia Grade 2/3: Critical Role of Duration of Infection. J Natl Cancer Inst. (102) 5: 315-324.

8. Schiffman M. Human papillomavirus testing in the prevention of cervical cancer. J Natl Cancer Inst. 2011 Mar 2;103(5):368-83. 